\title{
PELESTARIAN ARSITEKTUR LANGGAR DHUWUR MBAH YAI MASTUR LAMONGAN
}

\author{
Hammam Rofiqi Agustapraja ${ }^{1}$ \\ Program Studi Teknik Sipil, Fakultas Teknik, Universitas Islam Lamongan \\ Jln. Veteran 53 A, Lamongan, 62214 \\ Telepon. 08563183746, Faxs.0322-324706 \\ E-mail : hammamrofiqi@unisla.ac.id
}

\begin{abstract}
Langgar Dhuwur Mbah Yai Mastur is a lifted small mosque established by Hadratus Syaikh KH. Mastur Asnawi, until now it is still used for the activities of the Tahfidhul - Qur'an Islamic Boarding School, in terms of architecture, this building has different characteristics from the surrounding buildings, namely a simple design in the form of a stage made of wood and roofed with traditional roof (Limasan), so that the existence of meaning Historically this violation has not been eroded by development, so the need for research on architectural preservation with the consideration that this object has fulfilled the requirements of the Cultural Heritage Objects Act No. 11 of 2010, the method used to examine the preservation of architecture is a method of qualitative analysis using an approach with three methods, namely analysis description method, evaluative method and development method. The results of this study indicate that some visual elements of Langgar Dhuwur are still permanent, which can be known through observation on the object of study. Preservation directives for building visual elements are classified into three potential, namely low, medium and high potential, then from the three potential levels, preservation actions will be determined
\end{abstract}

\section{Keyword : Langgar Dhuwur, visual elements, Architectural Preservation, Lamongan}

\section{PENDAHULUAN}

Kota Lamongan merupakan salah satu kota tempat persebaran dan peradaban awal Islam di Jawa terutama di Jawa Timur, hal ini terlihat dengan adanya makam Sunan Drajat yang merupakan salah satu anggota dari walisongo, penyebaran Islam pun diteruskan oleh ulama-ulama penerusnya dan menyebar ke penjuru kabupaten dan kegiatan dakwah tersebut meninggalkan banyak peninggalan, salah satunya Langgar Dhuwur atau Langgar Panggung yang berada di jantung Kota Lamongan tepatnya di Jl. Kyai Amin 38, Sidokumpul, Lamongan. Langgar Dhuwur didirikan oleh KH. Mastur Asnawi atau yang lebih dikenal sebagai Mbah Yai Mastur sekitar tahun 1920-an dan sampai sekarang masih digunakan aktivitas keagamaan oleh pondok pesantren Tahfidhul - Qur'an.

Penelitian menggunakan objek studi Langgar Dhuwur Mbah Yai Mastur sebagai obyek penelitian pelestarian arsitektur karena sudah memenuhi kriteria Benda Cagar Budaya UU No. 11 Tahun 2010, yakni 1. berusia 50 (lima puluh) tahun atau lebih; 2. mewakili masa gaya paling singkat berusia 50 (lima puluh) tahun; 3. memiliki arti khusus bagi sejarah, ilmu pengetahuan, pendidikan, agama, dan/atau kebudayaan; dan 4. memiliki nilai budaya bagi penguatan kepribadian bangsa.

Usia dari Langgar Dhuwur ini sudah lebih dari 50 tahun, mewakili gaya arsitektur pada zaman tersebut dengan menggunakan struktur panggung karena kondisi Lamongan yang sering dilanda banjir, Langgar dhuwur juga memiliki nilai sejarah tentang dakwah dan peradaban Islam di Lamongan, sehingga menguatkan nilai-nilai budaya khususnya budaya Islami, pondok pesantren tradisional pada masyarakat Lamongan

Selain dari kriteria UU Benda Cagar Budaya tersebut, terdapat juga beberapa pertimbangan lain terhadap kriteria pemilihan objek penelitian, mengacu pada pendapat Pontoh (1992: 37) dalam Antariksa (2011), yakni 1. Kriteria Arsitektural: Suatu kota atau kawasan yang akan dipreservasikan atau konservasikan memiliki kriteria kualitas arsitektur yang tinggi, disamping memiliki proses pembentukan waktu yang lama atau keteraturan dan kebanggaan (elegance). 2. Kriteria Historis: Kawasan yang dikonservasikan memiliki nilai historis dan kelangkaan yang memberikan inspirasi dan referensi bagi kehadiran bangunan baru, meningkatkan vitalitas bahkan menghidupkan kembali keberadaannya yang memudar; dan 3 . Kriteria Simbolis: Kawasan yang memiliki makna simbolis paling efektif bagi pembentukan citra suatu kota

Berdasarkan uraian di atas, maka permasalahan yang akan dibahas dalam studi ini adalah bagaimana karakter visual bangunan utama serta strategi dalam upaya pelestarian bangunan Langgar Dhuwur Mbah Yai Mastur? Tujuan studi adalah untuk mengidentifikasi dan menganalisis karakter visual bangunan dan menganalisis serta menentukan strategi dalam upaya pelestarian bangunan Langgar Dhuwur Mbah Yai Mastur. 


\section{METODE}

Studi ini menggunakan metode analisis kualitatif dengan pendekatan menggunakan tiga metode. Metode pertama adalah metode deskripsi analisis, yaitu metode yang digunakan dengan menggambarkan objek penetian dan menganalisisnya dengan lebih jelas sehingga dapat diketahui karakter visual dari bangunan (Arikunto,1996). Sasaran utama penelitian mengenai karakter visual bangunan maka variabel penelitian yang digunakan terdiri atas elemen-elemen fasade dan elemen-elemen visual ruang dalam bangunan. (Tabel 1)

Tabel 1. Kriteria pengamatan, variabel dan Indikator

\begin{tabular}{|c|c|}
\hline \multicolumn{2}{|c|}{ Karakter visual, fasad bangunan } \\
\hline Atap & $\begin{array}{l}\text { Bentuk, Material, warna, perletakan, } \\
\text { perubahan }\end{array}$ \\
\hline Dinding & $\begin{array}{l}\text { Bentuk, Material, warna, perletakan, } \\
\text { perubahan }\end{array}$ \\
\hline Jendela & $\begin{array}{l}\text { Bentuk, Material, warna, arah unit } \\
\text { bukaan, perletakan, perubahan }\end{array}$ \\
\hline Pintu & $\begin{array}{l}\text { Bentuk, Material, warna, arah unit } \\
\text { bukaan, perletakan, perubahan }\end{array}$ \\
\hline Fasad & Jumlah, perubahan \\
\hline Kolom & $\begin{array}{l}\text { Komposisi: simetri, ritme/perulangan } \\
\text { Bentuk, Material, warna, perletakan, } \\
\text { perubahan }\end{array}$ \\
\hline
\end{tabular}

Metode kedua yang digunakan, yaitu metode evaluatif. Metode evaluatif digunakan untuk menentukan penilaian atau pembobotan terhadap kelayakan objek penelitian yang hasilnya berupa kesimpulan arahan serta strategi pelestarian yang sesuai. (Tabel 2)

Tabel 2. Kriteria Penliaian Langgar Dhuwur Mabah Yai Mastur (Antariksa, 2011) 1. Estetika $(E)$

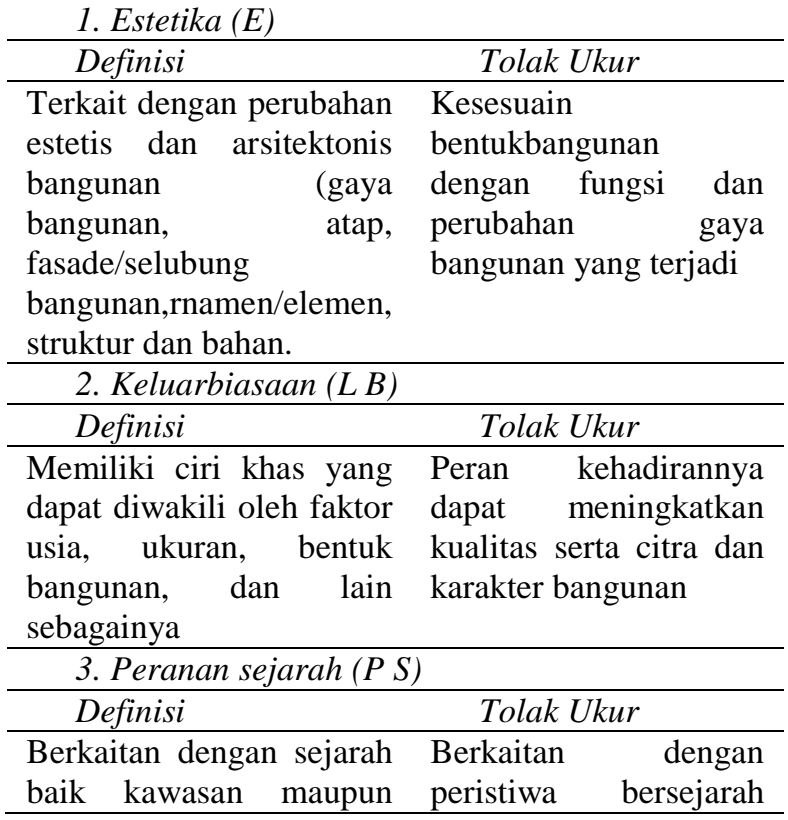

\begin{tabular}{|c|c|}
\hline bangunan itu sendiri & $\begin{array}{lr}\text { sebagai } & \text { hubungan } \\
\text { simbolis peristiwa } \\
\text { dahulu dan sekarang }\end{array}$ \\
\hline \multicolumn{2}{|l|}{ 4. Kelangkaan $(L K)$} \\
\hline Definisi & Tolak Ukur \\
\hline $\begin{array}{l}\text { Bentuk, gaya serta } \\
\text { elemen-elemen bangunan } \\
\text { dan penggunaan ornamen } \\
\text { yang berbeda dan tidak } \\
\text { terdapat pada bangunan } \\
\text { lain }\end{array}$ & $\begin{array}{l}\text { Merupakan bangunan } \\
\text { yang langka dan tidak } \\
\text { terdapat di daerah lain }\end{array}$ \\
\hline \multicolumn{2}{|c|}{ 5. Karakter Bangunan $(K B)$} \\
\hline Definisi & Tolak Ukur \\
\hline $\begin{array}{l}\begin{array}{l}\text { Memiliki peran } \begin{array}{r}\text { yang } \\
\text { dalam }\end{array} \\
\text { penting } \\
\text { pembentukan } \\
\text { bangunan }\end{array} \\
\text { karakter }\end{array}$ & $\begin{array}{l}\text { Memiliki ciri khas } \\
\text { seperti usia bangunan, } \\
\text { ukuran/luas bangunan, } \\
\text { bentuk bangunan, dan } \\
\text { sebagainya }\end{array}$ \\
\hline \multicolumn{2}{|c|}{ 6. Memperkuat citra kawasan (C K) } \\
\hline Definisi & Tolak Ukur \\
\hline $\begin{array}{l}\begin{array}{l}\text { Memiliki peran } \begin{array}{r}\text { yang } \\
\text { dalam }\end{array} \\
\text { penting } \\
\text { pembentukan } \\
\text { kawasan }\end{array} \\
\text { karakter }\end{array}$ & $\begin{array}{l}\text { Peran kehadirannya } \\
\text { dapat sesuai dengan } \\
\text { fungsi kawasan dan } \\
\text { meningkatkan kualitas } \\
\text { serta citra dan karakter } \\
\text { kawasan }\end{array}$ \\
\hline
\end{tabular}

Setelah melakukan penilaian pada masingmasing kriteria, nantinya akan dijumlahkan untuk memperoleh nilai total yang dimiliki oleh tiap elemen bangunan. Nilai ini sebagai patokan dalam klasifikasi elemen yang selanjutnya menjadi dasar dalam penentuan arahan pelestarian.

Langkah-langkah dalam penilaian makna kultural bangunan sebagai berikut:

1. Menjumlahkan hasil dari masing-masing kriteria.

2. Menentukan total nilai tertinggi dan terendah.

3. Total nilai tertinggi sesuai dengan penilaian makna kultural pada bangunan dalam penelitian ini adalah 18 , sedangkan total nilai terendah adalah 6 .

4. Menentukan jumlah kelas dengan rumus Sturgess, mengemukakan bahwa sebuah rumus guna menentukan kelas yang sebaiknya digunakan dalam penggolongan data.

Rumus Sturgess

$\mathrm{k}=1+3,322 \log \mathrm{n}$

$\mathrm{k}=1+3,322 \log 6=3,58$ dibulatkan menjadi 3

Keterangan:

$\mathrm{k}: \Sigma$ Kelas

$\mathrm{n}: \Sigma$ angka yang terdapat dalam data

5. Menentukan pembagian jarak interval dengan cara selisih antara total nilai tertinggi dan total nilai terendah untuk 
kemudian dibagi dengan jumlah kelas, seperti:

$\mathrm{i}=\frac{\mathrm{Jarak}}{\mathrm{k}}=\frac{12}{3}=4$

Keterangan:

i : interval kelas

jarak : rentang nilai tertinggi dan terendah

- Mendistribusikan setiap total nilai ke dalam klasifikasi sesuai jarak interval (Tabel 3).

Tabel 3 Kelompok Penilaian

\begin{tabular}{cc}
\hline Penilaian & Keterangan \\
\hline Nilai $<10$ & Potensial rendah \\
Nilai $11-15$ & Potensial Sedang \\
Nilai $>15$ & Potensial Tinggi \\
\hline
\end{tabular}

Metode ketiga yang digunakan adalah metode developmen (pengembangan). Metode developmen dilakukan untuk menentukan arahan dalam upaya konservasi bangunan, dalam hal ini Langgar Dhuwur Mbah Yai Mastur untuk membandingkan data dengan kriteria atau standar yang sudah ditetapkan saat penyusunan desain penelitian. Standar yang ditetapkan adalah penetapan arahan yang dilakukan dengan cara menyesuaikan hasil analisis terhadap bangunan dengan teori pelestarian yang dijelaskan oleh para ahli serta bentuk-bentuk arahan yang telah diterapkan pada kondisi yang sama dengan kondisi penelitian.

Arahan tindakan fisik pelestarian digunakan untuk menentukan batas perubahan fisik yang diperbolehkan bagi tiap-tiap elemen arsitektural Langgar Dhuwur Mbah Yai Mastur. Hasil dari evaluasi yang telah diperoleh melalui penilaian makna kultural bangunan menjadi landasan dalam menggolongkan strategi pelestarian (Tabel 4)

Tabel 4 Teknik Pelestarian Fisik

1. Potensial Tinggi

Tingkat Perubahan Fisik Arahan Pelestarian Fisik yang diperbolehkan

\begin{tabular}{|c|c|}
\hline Sangat Kecil & Preservasi \\
\hline \multicolumn{2}{|l|}{ 2. Potensial Sedang } \\
\hline $\begin{array}{l}\text { Tingkat Perubahan Fisik } \\
\text { yang diperbolehkan }\end{array}$ & Arahan Pelestarian Fisik \\
\hline Kecil & Konservasi, rehabilitasi \\
\hline \multicolumn{2}{|l|}{ 2. Potensial Sedang } \\
\hline $\begin{array}{l}\text { Tingkat Perubahan Fisik } \\
\text { yang diperbolehkan }\end{array}$ & Arahan Pelestarian Fisik \\
\hline Sedang-besar & Rehabilitasi \\
\hline
\end{tabular}

\section{PEMBAHASAN}

Langgar Dhuwur Mbah Yai Mastur merupakan artefak peninggalan dakwah Islam di Kota Lamongan, didirikan sekitar tahun 1920an, pendirinya adalah KH Mastur Asnawi yaitu seorang ulama karismatik yang juga pendiri Masjid Agung Lamongan (Wafiyyah, 2017).

Secara Arsitektur, bangunan ini merupakan bangunan sederhana, yang memiliki karakter peninggian lantai atau panggung, yang mengadaptasi kondisi lamongan yang sering terjadi banjir, peninggian bangunan ini juga terlihat pada bangunan kelas peninggalan Belanda pada Sekolah SMPN 1 Lamongan, yang memiliki karakteristik yang sama yaitu peninggian lantai atau panggung.

Penelitian ini merupakan upaya pelestarian Langgar Dhuwur Mbah Yai Mastur, agar bisa terawat nilianilai historisnya, melalui analisis Karakter Visual Bangunan, Tinjauan Pelestariannya, Arahan Fisik Pelestariannya.

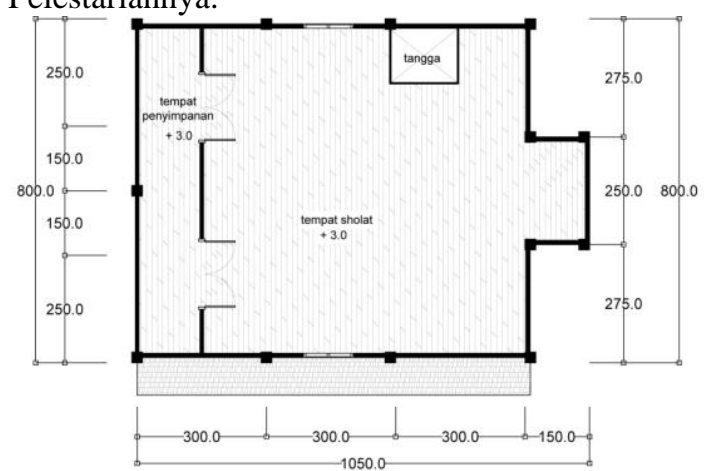

Gambar 1. Denah Langgar Dhuwur

\subsection{Karakter Visual Bangunan}

1. Elemen Fasad Bangunan

a Atap

Bentuk atap bangunan ini memiliki bentuk atap tradisional berbentuk limasan, terdapat pembagian atap, atap utama menutupi bagian utama langgar, seluruh tempat sholat tertutup atap utama, atap yang menutupi bagian imam sholat, dan atap tritisan untuk mencegah tampias hujan agar tidak membasahi lantai bawah.

Konstruksi atap menggunakan kuda-kuda kayu, sedangkan material penutup atapnya menggunakan genteng, warna coklat kemerahan, tetapi karena termakan oleh usia warna menjadi menghitam,

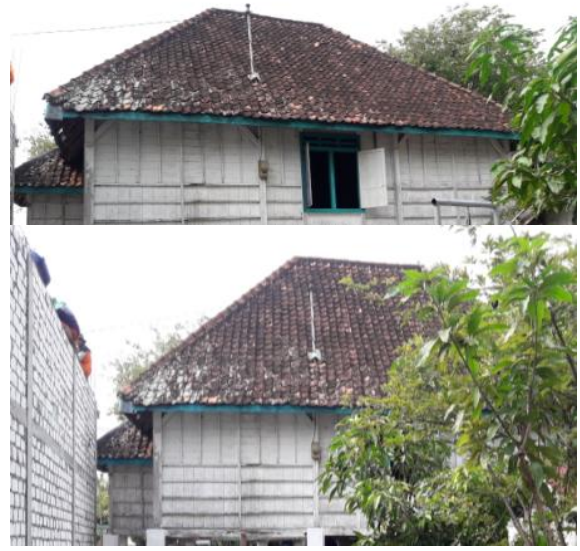

Gambar 2. Atap Utama dan Atap Ruang Imam 
Atap yang menaungi tempat imam, menjorok ke lahan tetangga, sehingga perlu diperbaiki karena air yang mengalir dari atap tersebut bisa merugikan orang lain.
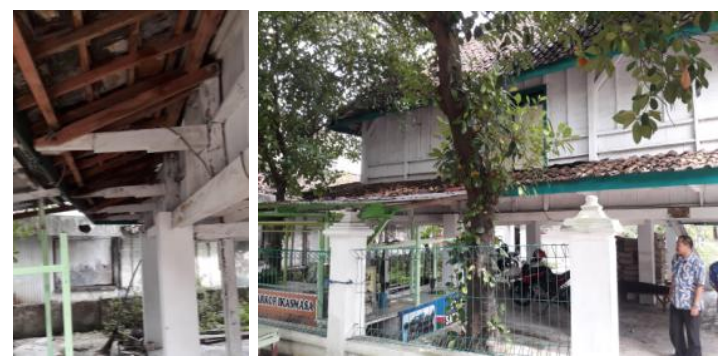

\section{Gambar 3. Atap Tritisan yang ada pada sisi Utara}

\section{b. Dinding}

Dinding bangunan ini menggunakan material kayu papan yang disusun vertikal pada separuh bagian bawah dan horisontal pada separuh bagian atas, dengan pemasangan rata dalam sehingga terlihat tiang kayu penyangga dari luar. Dinding kayu ini tidak terdapat ornamen pada bagian luar maupun bagian dalam, hanya menggunakan finishing cat ada bagian dalamnya.
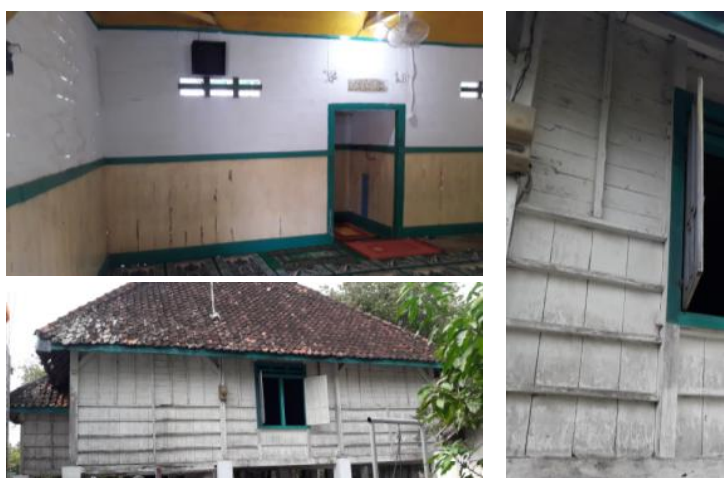

Gambar 4. Dinding Kayu Tampak Interior (Atas) dan Tampak Eksterior (Bawah)

c. Pintu

Bangunan ini cukup unik, karena tidak memiliki pintu utama, karena akses masuk melalui tangga dengan kemiringan yang cukup tegak dan terbuat dari kayu, terdapat pintu hanya pada bagian dalam masjid, yaitu itu masuk ke areal gudang dan tempat penyimpanan, pintu sendiri terbuat dari kayu dengan tinggi keseluruhan $220 \mathrm{~cm}$, tinggi daun pintu $170 \mathrm{~cm}$ dan tinggi kisi-kisi atas $50 \mathrm{~cm}$ dengan lebar keseluruhan $80 \mathrm{~cm}$, terdiri dari dua daun pintu yang masing-masing lebar $40 \mathrm{~cm}$, yang di-finishing dengan menggunakan cat.

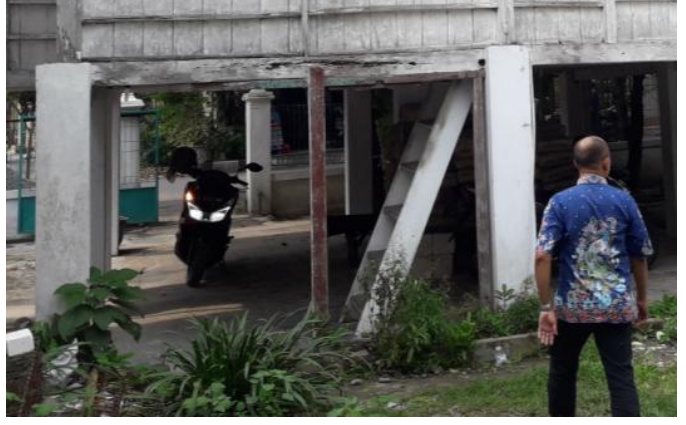

Gambar 5. Tangga Pintu Masuk Utama
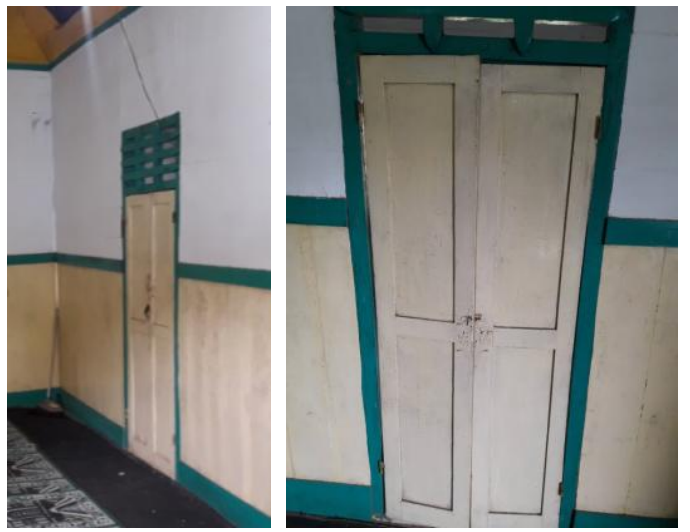

Gambar 6. Pintu Yang Berada di Dalam Langgar

d. Jendela

Bangunan ini memiliki 2 jendela utama yang berada disisi bangunan utama, jendela tersebut memiliki 2 daun jendela, yang masing-masing mempunyai tinggi $150 \mathrm{~cm}$ yang terdiri dari $120 \mathrm{~cm}$ tinggi daun jendela dan $30 \mathrm{~cm}$ tinggi kisi-kisi jendela, lebar jendela $120 \mathrm{~cm}$, terdiri dua daun jendela yang masing masing daun jendela lebarnya $60 \mathrm{~cm}$. Material jendela terbuat dari kayu, di atas daun jendelanya memiliki kisi-kisi, yang memiliki fungsi mengalirkan udara masuk ke dalam bangunan jika jendela tersebut ditutup.
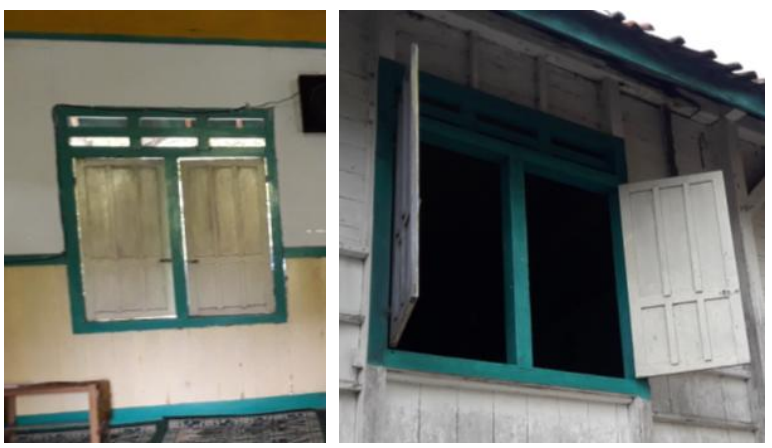

Gambar 7. Jendela Dengan Bukaan Keluar 
e. Fasad

Fasad dari bangunan ini simetris antara kanan dan kiri sama jika dibelah dari arah timur ke barat, tidak terdapat ornamen-ornamen yang menjadi khusus dari bangunan ini termasuk ornamen atap, dinding, pintu, maupun jendela. Yang menjadi ciri khas fasad dari bangunan ini adalah berbentuk panggung, tidak ada bangunan di bawahnya, hal tersebut di karenakan pada zaman itu Lamongan masih sering dilanda banjir, dan menjadi kearifan lokal bila bangunan diangkat ke atas untuk menghidari banjir.

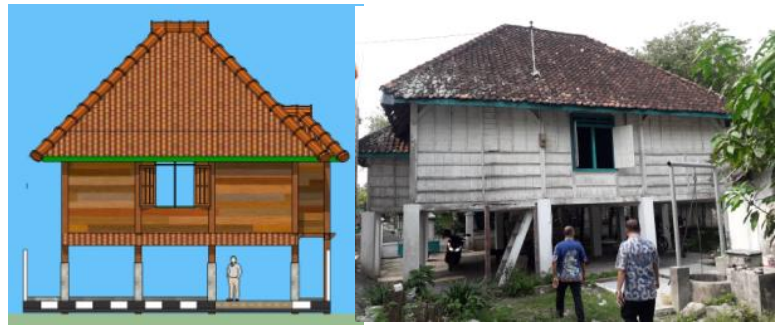

\section{Gambar 8. Fasad Tampilan muka Langgar Dhuwur Mbah Yai Mastur}

\section{f. Kolom}

Kolom pada bangunan ini menggunakan material yang berbeda, sebagai kolom panggungnya menggunakan material kolom beton dan bagian langgarnya masih menggunakan kolom kayu, kolom beton tersebut merupakan bagian dari perbaikan dari Bupati KH. Moch. Faried, SH. (pada masa jabatan 1989-1999) untuk mengganti kolom kayu yang sudah termakan usia,

Tidak ada ornamen pada kolom, hanya kolom polos dan sederhana.

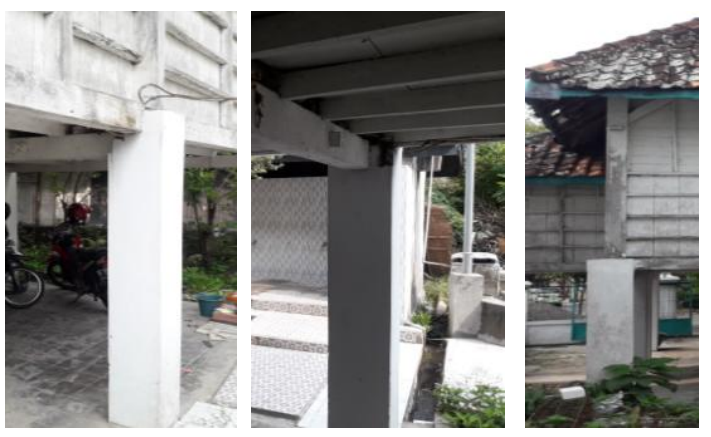

Gambar 9. Kolom Beton dan Tiang Kayu

\subsection{Tinjauan Pelestarian Langgar Dhuwur Mbah Yai Mastur}

Analisis elemen bangunan potensial dilakukan dengan cara penilaian makna kultural bangunan. Bentuk penilaian dilakukan dengan cara memberikan bobot nilai pada setiap kriteria makna kultural yang terbagi dalam tiga kelas, yaitu tinggi, sedang, dan rendah dengan nilai 3, 2, dan 1. Dalam memudahkan penghitungan tersebut dilakukan rekapitulasi terhadap penilaian makna kultural (Tabel 5 dan Tabel 6).
Tabel 5 Rekapitulasi Nilai Makna Kultural Bangunan

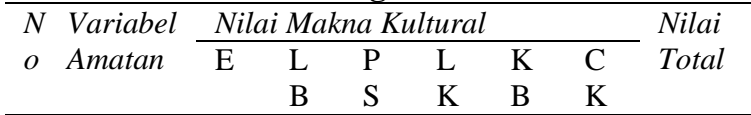

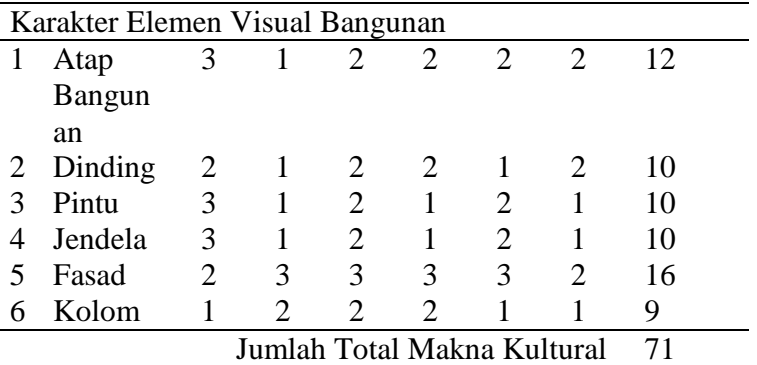

Tabel 6 Potensial Elemen Visual Fasad Langgar Dhuwur Mbah Yai Mastur

\begin{tabular}{llll}
\hline No & Variabel Amatan & $\begin{array}{l}\text { Nilai } \\
\text { Total }\end{array}$ & Kelas \\
\hline 1 & Atap Bangunan & 12 & Potensial Sedang \\
2 & Dinding & 14 & Potensial Sedang \\
3 & Pintu & 10 & Potensial Rendah \\
4 & Jendela & 10 & Potensial Rendah \\
5 & Fasad & 16 & Potensial Tinggi \\
6 & Kolom & 9 & Potensial Rendah
\end{tabular}

\subsection{Arahan Fisik Pelestarian Langgar Dhuwur Mbah Yai Mastur}

Analisi Langgar Dhuwur Mbah Yai Mastur menghasilkan klasifikasi potensial elemen-elemen bangunan berdasarkan nilai makna kultural yang terdapat pada masing-masing kelas. Hasil dari klasifikasi potensial tersebut menunjukkan tingkat prioritas elemen-elemen bangunan. Selain itu hasil klasifikasi potensial elemen bangunan dapat menentukan tindakan pelestarian fisik berupa arahan kebijakan berupa preservasi, konservasi dan rehabilitasi.

Berikut klasifikasi elemen bangunan potensial dan arahan fisik pelestarian berdasarkan hasil analisis:

a. Potensial tinggi 16-18:

Fasad adalah adalah Elemen visual yang memiliki niai potensial tertinggi, karena fasad atau tampilan bangunan masih mempunyai karakteristik yang sama dari bangunan awal, walaupun ada beberapakali upaya perawatan dan perbaikan, untuk upaya pelestarian elemen yang potensial tinggi, yaitu preservasi. Preservasi merupakan upaya pelestarian yang dilakuan dengan tujuan mencegah proses kerusakan pada bangunan serta elemen-elemennya dengan hanya melakukan sedikit perubahan hingga tidak melakukan perubahan sama sekali tetap mempertimbangkan hubungan antara kegiatan preservasi dengan perkembangan bangunan dimasa mendatang, dengan kata lain, pelestarian harus tetap menjaga karakteristik fasad dari Langgar Dhuwur tersebut yaitu bangunan panggung, dengan elemen kayu yang dominan. 
b. Potensial sedang 15-11:

Elemen visual yang memiliki nilai potensial sedang, yaitu atap dengan nilai 12, Tindakan pelestarian yang disarankan pada elemen bangunan yang memiliki nilai potensial sedang, yaitu konservasi. Konservasi ini merupakan upaya pelestarian di mana elemen-elemen bangunan yang masih ada dan kondisinya masih bagus atau terawat dipertahankan fungsi dan penggunaannya sehingga dapat dimanfaatkan dengan baik di masa depan.

c. Potensial rendah 6-10:

Elemen visual dengan potensial rendah, yaitu kolom termasuk kolom beton dan kayu dengan nilai 9, Pintu dan Jendela masing-masing memiliki nilai 10 dan dinding kayu dengan nilai 10. Tindakan pelestarian yang disarankan pada elemen bangunan yang memiliki nilai potensial rendah, yaitu rehabilitasi. Rehabilitasi merupakan upaya pelestarian yang dilakukan dengan cara mengembalikan/memperbaiki kondisi bangunan ataupun elemen-elemen bangunan yang telah mengalami kerusakan ataupun penurunan kondisi fisik untuk dapat kembali seperti keadaan semula sehingga dapat berfungsi kembali sebagaimana mestinya.

\section{KESIMPULAN}

Karakter visual bangunan didominasi oleh elemen arsitektural dengan material kayu sehingga untuk pelestarian diperlukan Rehabilitasi yaitu mengembalikan/memperbaiki kondisi bangunan ataupun elemen-elemen bangunan yang telah mengalami kerusakan ataupun penurunan kondisi fisik untuk dapat kembali seperti keadaan semula sehingga dapat berfungsi kembali sebagaimana mestinya, tetapi tidak dengan merubah karakter bangunan yang sederhana, terbuat dari material kayu dan memiliki lantai panggung, sehingga nilai-nilai sejarah dan budaya masih bisa diwariskan oleh generasi mendetang.

\section{PUSTAKA}

Agustapraja, Hammam Rofiqi. 2018. Studi Pemetaan Perilaku, Pejalan Kaki pada Pedestrian Alun-alun Kota Lamongan, Jurnal Civilla 3(1), 134-139

Antariksa. 2011. Metode Pelestarian Arsitektur. www.academia.edu

Arikunto, Suharsimi. 1996. Prosedur Penelitian Suatu Pendekatan Praktek. Jakarta: PT. Rineka Cipta arsitektur e-Journal, Volume 7 Nomor 1, Juni 201451

Handinoto. 1994. "INDISCHE EMPIRE STYLE" Gaya Arsitektur "Tempo Doeloe" Yang Sekarang Sudah Mulai Punah. Jurnal Dimensi Teknik Arsitektur

Krier, Rob. 2001. Komposisi Arsitektur. Jakarta: Erlangga. RTRW Kota Madiun 2010-2030
Sari, Vony Mayanti Novita. 2016. KH. MASTUR ASNAWI: STUDI PERAN SOSIAL KEAGAMAAN PADA MASYARAKAT KOTA LAMONGAN TAHUN 19191982. Undergraduate thesis, UIN Sunan Ampel Surabaya

Sukarno, Pipiet Gayatri., Antariksa, Noviani Suryasari, 2014. Pelestarian Bangunan Kolonial Belanda Rumah Dinas Bakorwil Kota Madiun. arsitektur e-Journal, Volume 7 Nomor 1, Juni 2014

Sumalyo, Yulianto. 2001. Arsitektur Mesjid dan Monumen Sejarah Muslim. Gadjah Mada University Press

Tugiyono, dkk. 2001. Peninggalan Situs dan Bangunan Bercorak Islam di Indonesia.Jakarta:PT. Mutiara Sumber Widya.

Wafiyyah, Siti Kulashatul. 2017. Perkembangan Arsitektur Masjid Agung Lamongan. Fakultas Adab dan Humaniora, Universitas Islam Negeri Sunan Ampel Surabaya 